\title{
Roman bazaar or market economy? Explaining tableware distributions through computational modelling
}

Tom Brughmans ${ }^{1,2} \&$ Jeroen Poblome ${ }^{3}$

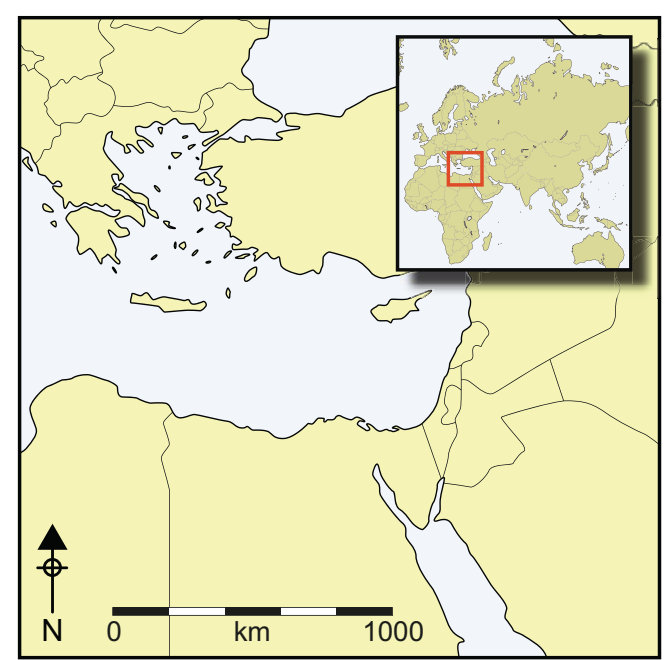

How closely integrated were the commercial centres of the Roman world? Were traders aware of supply and demand for goods in other cities, or were communities of traders in cities protectionist and working opportunistically? Widely traded commodities such as terra sigillata tablewares in the Eastern Mediterranean provide an ideal opportunity to explore the economic processes that underlie the archaeological evidence. Agent-based computational modelling allows various such processes to be explored, and also identifies areas for further investigation.

Keywords: Eastern Mediterranean, Roman, tableware, agent-based model, trade

\section{Introduction}

Ceramic tableware is one of the most common finds on Roman archaeological sites, and it lends itself to quantification. This study draws on the published evidence of Roman tableware from the Eastern Mediterranean to explore a particularly robust distribution pattern and understand the past social mechanisms that might have created it. The pattern under scrutiny here is the very wide distribution of four distinct wares: Eastern Sigillata A, $\mathrm{B}, \mathrm{C}$ and D (abbreviated as ESA, ESB, ESC and ESD respectively). All four wares were produced and circulated in the Roman East between late Hellenistic times and $c$. AD 150, but only one ware maintained a supra-regional distribution for centuries: ESA.

1 Department of Computer and Information Science, University of Konstanz, Box 67, Konstanz 78457, Germany (Email: tom.brughmans@uni-konstanz.de)

2 Archaeological Computing Research Group, Faculty of Humanities, University of Southampton, Avenue Campus, Highfield, Southampton SO17 1BF, UK

3 Sagalassos Archaeological Research Project, University of Leuven, Leuven, Belgium (Email: jeroen.poblome@ arts.kuleuven.be) 
Archaeologists have formulated many hypotheses to explain this distribution pattern: a dependency on state structures, the role of redistributive centres, consumption or 'pulling forces', commercial 'piggy-back' trade and a proximity to large-scale agricultural production (e.g. Abadie-Reynal 1989; Reynolds 1995; Lewit 2011; Bes 2015). A summary of these is provided by Philip Bes (2015), who argues that four mutually dependent factors may underpin the supra-regional distribution pattern of tablewares:

1. The symbiosis between an active urban hub and its productive hinterland.

2. The pulling forces exerted by important regional centres with political administrative, economic, religious and military functions, or a combination of these, such as Delos, Corinth and Alexandria.

3. Patterns of communication between people, resulting in interconnected places.

4. A political or other type of system that establishes or maintains these factors.

Most scholars agree that a complex mix of mechanisms working on multiple levels was responsible for the differences in tableware distribution patterns, and have formulated these as descriptive conceptual models for explaining the functioning of Roman trade (e.g. Bes 2015). As there is no shortage of hypotheses, the key research aim in the study of tableware distribution processes should be to identify which of the factors, or combinations of factors, is best supported by the available evidence: to explore the middle ground, or 'grey zone', between more extreme hypotheses. The development of conceptual models has not, however, gone hand in hand with the adoption of methodological approaches that allow distinctions to be made between archaeological signatures for different scenarios (Davies 2005; Morris et al. 2007; although see Graham \& Weingart 2015 for a notable exception).

Our contribution to this ongoing discussion evaluates conceptual models by combining an exploratory analysis of the published tableware evidence with computational modelling of hypothetical distribution mechanisms. The particular focus will be on evaluating aspects of two influential conceptual models: Peter Bang's (2008) 'Roman bazaar' and Peter Temin's (2013) 'Roman market economy'.

In Bang's model, the integration of markets around the empire was weak, meaning that traders had poor knowledge of prices and the availability of goods. Moreover, according to Bang's hypothesis, the flow of goods and commercial information was structured by the opportunistic and protectionist communities of traders. By contrast, in Temin's model, markets were more strongly integrated, and commercial information from one market was more easily accessible in other markets. The concept of social networks connecting commercial actors and enabling the flow of commercial information and goods is central to both scenarios. The social networks of traders are, however, incorporated very differently in both models: the influence of community structure on markets is emphasised in Bang's model, and in Temin's, emphasis is placed on the ability for information to pass among social contacts between markets more easily.

The potential role of social networks as a driving force in the Roman trade system can be explored by formalising Bang's and Temin's hypotheses, and determining what archaeological distribution patterns one would expect of them. Tableware trade in the Roman East is considered to have functioned as a complex system, where the small-scale

(C) Antiquity Publications Ltd, 2016 
Table 1. Typo-chronological references and possible region of production for major Eastern tablewares.

\begin{tabular}{|c|c|c|c|}
\hline Ware & Abbreviation & $\begin{array}{l}\text { Typological and } \\
\text { chronological standard }\end{array}$ & $\begin{array}{l}\text { Region of production, } \\
\text { based on Schneider } 2000\end{array}$ \\
\hline $\begin{array}{l}\text { Eastern } \\
\quad \text { Sigillata A }\end{array}$ & ESA & Hayes 1985 & $\begin{array}{l}\text { Coast between Tarsos (TUR) and Latakia } \\
\text { (SYR) }\end{array}$ \\
\hline $\begin{array}{l}\text { Eastern } \\
\quad \text { Sigillata B }\end{array}$ & ESB & Hayes 1985 & $\begin{array}{l}\text { Maeander Valley in western Asia Minor } \\
\text { (TUR); possibly Aydin (ancient Tralleis) }\end{array}$ \\
\hline $\begin{array}{l}\text { Eastern } \\
\quad \text { Sigillata C }\end{array}$ & ESC & $\begin{array}{l}\text { Hayes } 1972,1985 \text { and } \\
\quad \text { Meyer-Schlichtmann } 1988\end{array}$ & Pergamon and surrounding region \\
\hline $\begin{array}{l}\text { Eastern } \\
\quad \text { Sigillata D }\end{array}$ & ESD & Hayes 1985 & Cyprus (probably the western part) \\
\hline
\end{tabular}

actions and interactions of agents, with only limited access to information, gave rise to largescale patterns that allow comparison with the archaeological record. In doing so, we also highlight the potential of computational modelling in Roman archaeology for evaluating the implications of hypothetical processes operating on multiple levels in order to understand the observed large-scale distribution patterns of ceramics better.

\section{Data: tableware distribution in the Roman East}

The analysis presented here will focus on four major types of Hellenistic and Roman Imperial Red Slip tablewares, commonly referred to as terra sigillata: ESA, ESB, ESC and ESD. Each of these four wares was produced in huge volumes in large manufactories in the Eastern Mediterranean, and was widely distributed, but ESA had a significantly wider distribution than the other three. The differences in tableware production outputs need to be understood within an ancient economic context. Most tablewares were small-scale artisanal productions, yet in the case of the four eastern sigillatas studied here, the production output as well as the associated employment of the available means was on a large scale. The significant investment in the production of these wares created opportunities for diversification in economic activity in the context of a system heavily geared towards, and dependent upon, agriculture (Poblome 2013).

Work by the ICRATES project ('Inventory of Crafts and Trade in the Roman East') led to the creation of a database of over 33000 tableware sherds recorded in published sources. The creation, structure and limitations of the ICRATES dataset are discussed in Bes and Poblome (2008). The period between $25 \mathrm{BC}$ and AD 150 is when all four tablewares were circulated in the Eastern Mediterranean. All sherds that fall within these chronological limits were extracted from the ICRATES database as a subset of 5121 sherds from 222 sites in the Eastern Mediterranean. The standard typological and chronological frameworks of tableware forms shown in Table 1 were used. Given that the dating ranges of tableware forms differ in length, we used the method described by Fentress and Perkins (1988), and discussed in detail by Willet (2014), to divide the dataset into 25-year periods. We assumed a normal distribution for the popularity and circulation of tableware forms, although very 
Normalised number of sites with wares per period

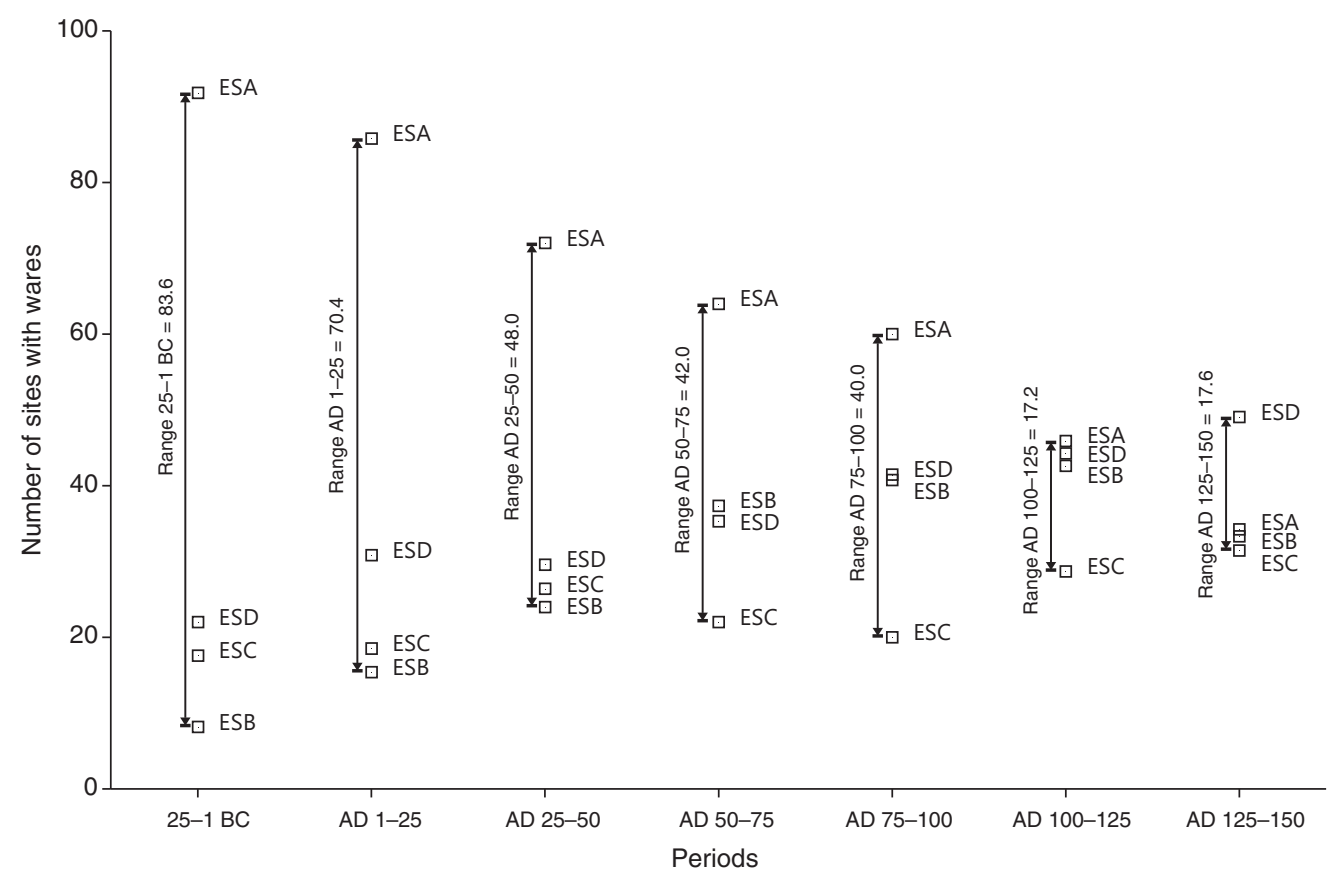

Figure 1. The number of sites each ware is attested at per 25-year period; the dataset of ceramics used is available as supplement 1 ( $n=5121$ tableware sherds); values were normalised to a scale of 100 sites $(n=222)$ to facilitate comparison with the simulated distributions in Figures 6 and 8; ESA is attested on far more sites than the other three wares for the period of $25 B C-A D 75$.

similar results are obtained when assuming a uniform distribution (Brughmans \& Poblome 2016a). This method allows us to explore changing distribution patterns of tableware forms through time. The resulting 25-year period datasets used in this paper are available as online supplementary material (Table $\mathrm{S} 1$ ).

An exploratory analysis of this dataset made it clear that many of the weaker patterns detected are a result of modern biases, including: the use of particular typological and chronological frameworks; the geographic limitations of the dataset; differences in the number of published excavations across the study area (which do not correspond to ancient patterns of settlement hierarchies); or the common practice of only publishing diagnostic sherds. Therefore, only the broader patterns and trends of wares in this dataset can be considered robust and comparable over a large geographic area. These biases mean that critical quantitative comparison of the proportions of sherds and forms in site assemblages, or attempts at understanding the specific roles of sites, and even the larger hubs, is considered impossible.

ESA has by far the widest distribution until at least $\mathrm{AD} 75$; it is found at far more sites than the other wares (Figure 1). After AD 75, the extent of its distribution gradually decreased, while that of ESB and ESD slowly increased over the period AD 50-125. Between $c$. AD (C) Antiquity Publications Ltd, 2016 


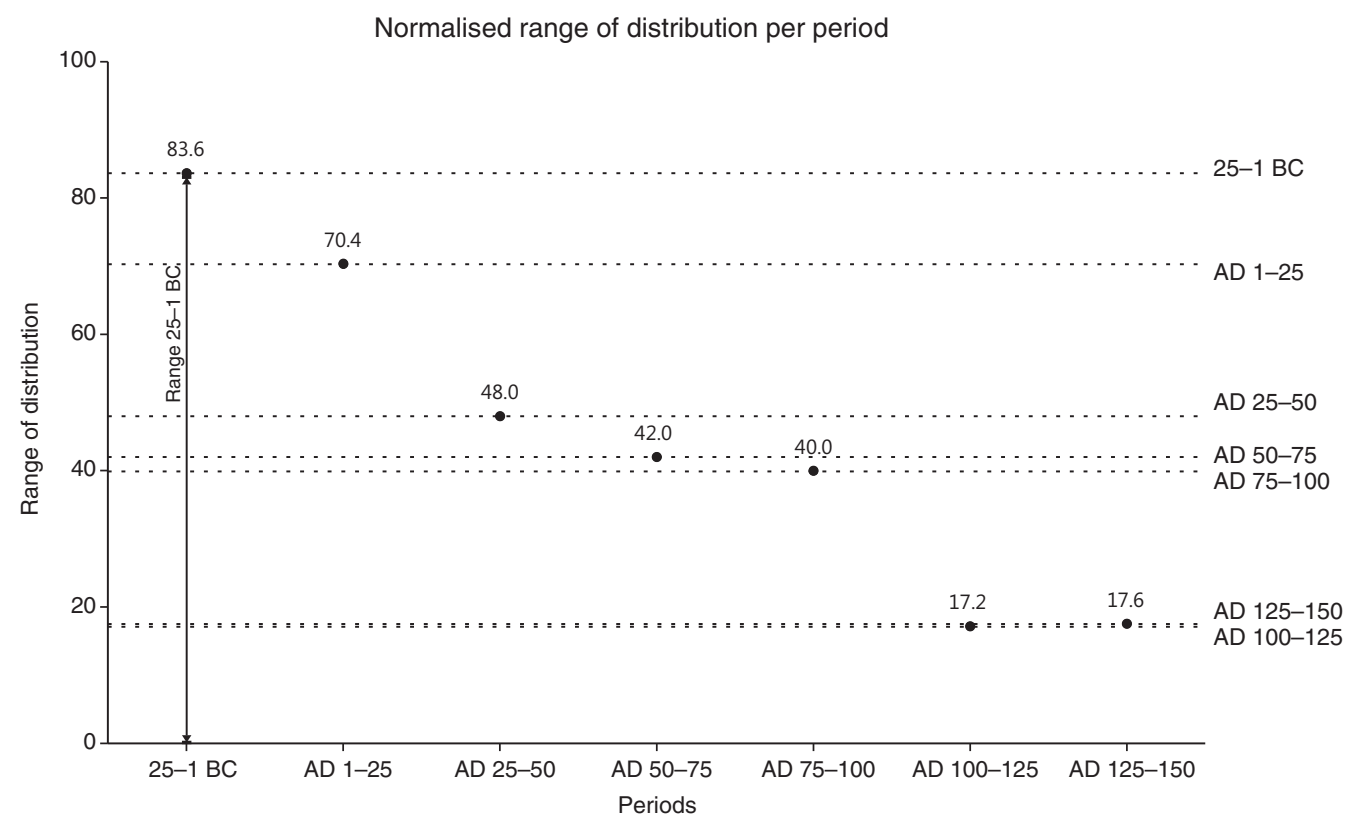

Figure 2. The difference between the most and least widely distributed wares (i.e. the range of distribution) was initially very large and decreased steadily throughout the period of study (the dashed lines will be used for comparison with the simulated ranges in Figures 5 \& 7 ).

100 and 150, ESD overtakes ESA with a wider distribution, but the difference between ESD and other wares is not as strongly pronounced, as in the case of the earlier ESA distribution. This is also reflected in the histogram in Figure 2, which represents the range of distribution per period, defined as the maximum distribution width of a ware minus the minimum distribution width of another ware.

The changes in the range of distribution further emphasise the exceptional difference between ESA and other wares, which gradually diminishes. Finally, another broad pattern may be discerned. The frequency distributions of the number of wares per site in Figure 3 show few differences over time: the vast majority of sites have evidence of only one ware, while a small number of sites have evidence of two, three or four wares.

\section{Tableware distribution processes and social networks}

\section{Bang's model: the Roman bazaar in a tributary empire}

Bang (2008) argues that markets in Roman Imperial times functioned very differently to those of the present day, which are dominated by large-scale, integrated entities where well informed, specialist trade is facilitated by extensive and efficient communication networks. Instead, Bang suggests the concept of bazaar-style markets as

distinguished by high uncertainty of information and relative unpredictability of supply and demand. This makes the prices of commodities in the bazaar fairly volatile. As a 
Frequency distribution of number of wares per site
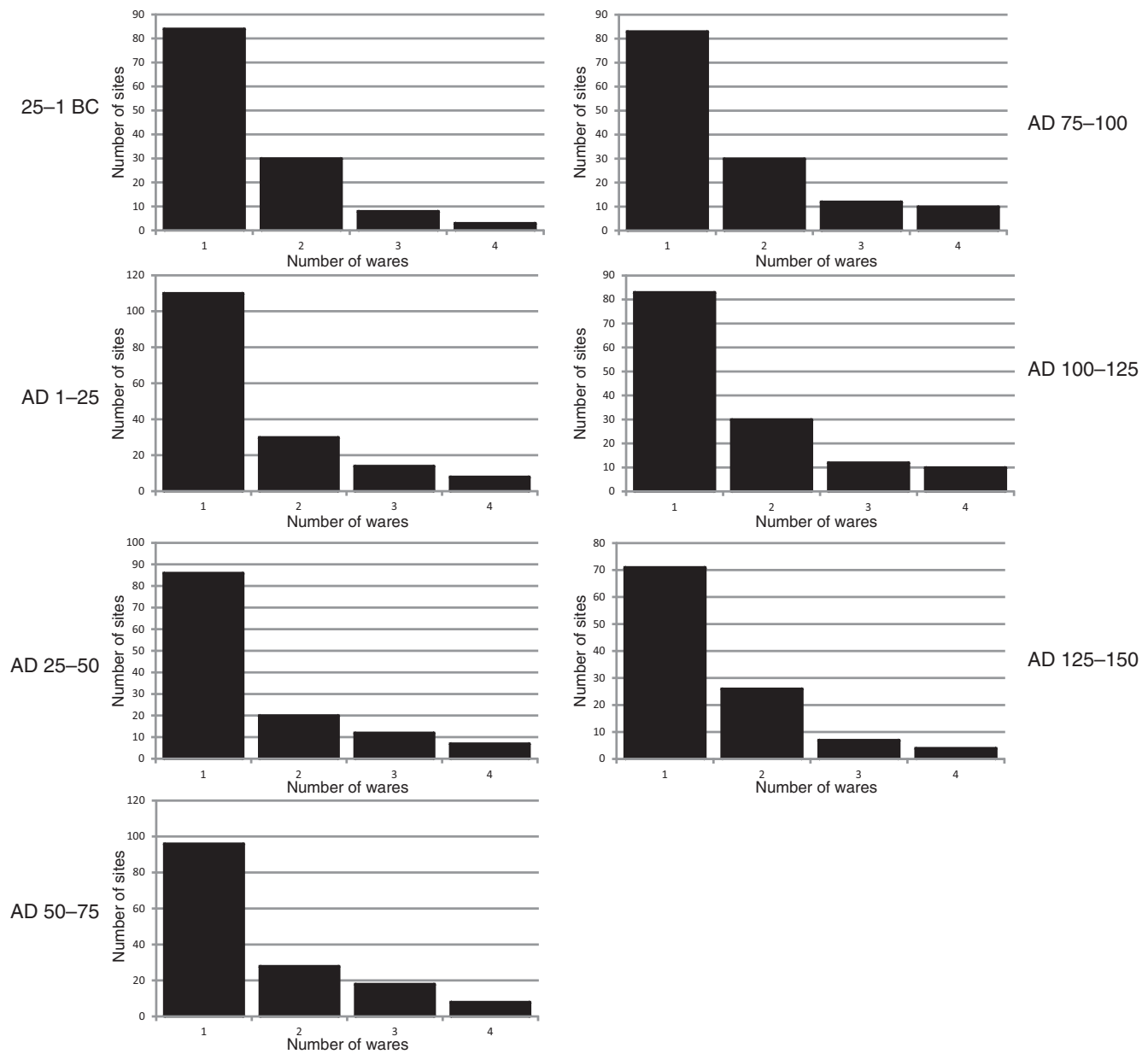

Figure 3. Frequency distribution per 25-year period of the number of sites at which 1,2, 3 or 4 wares were attested; unlike Figures 1-2, these frequency distributions do not use a normalised number of sites $(n=222)$; most sites have evidence of only one ware.

consequence, the integration of markets is often low and fragile; it is simply difficult for traders to obtain sufficiently reliable and stable information on which effectively to respond to developments in other markets. Considerable fragmentation of markets prevails (Bang 2008: 4).

This model sees the Roman market as a fragmentary system with low standardisation, of which traders have very limited knowledge. The agents braving this rugged landscape of trade were faced with a variety of challenges. Due to variable consumer demands, production supplies, environmental uncertainties and transport challenges, the market experienced huge disturbances and low transparency. Responses to these challenges were twofold: instead of market integration, merchants would aim to benefit from opportunism and speculation;

(C) Antiquity Publications Ltd, 2016 
and a social network of personal trusted relations and strong communal ties was maintained. This network provided protection (both commercial and physical), and, to a large extent, determined the information available to the agent as well as their economic opportunities (Bang 2008: 200-201). Such social networks allowed inter-regional trade to take place through an integration of political and commercial spheres, as well as the specialisation of intermediaries. Even if the merchants roamed far away from home, the dominating tendency was for communities to form and be structured around native identities, mainly in the larger and more active urban centres in the area.

This mechanism is illustrative of the local emergence of social networks, often with a preference for native connections but giving rise to a supra-regional distribution of goods (Bang 2008: 249-50). The community structure of social networks served to protect community interests and opportunism while disadvantaging outsiders, thus reinforcing the fragmentation of the Roman market system. Bang's model therefore offers a mechanism for exchange that works bottom-up through individual interactions, yet does not disregard the emergence of large-scale distribution patterns. This model can be used as a possible explanatory mechanism for differences in tableware distribution patterns, which are interpreted as pointing to the existence of different localised social networks that are only intertwined to a very limited extent (Bang 2008: 288). Two other major components of Bang's model, the tributary nature of the Roman Empire and the 'agrarianate' nature of its societies, are not explicitly addressed in this study, which primarily focuses on the role played by social networks in supra-regional trade (Bang 2008: 288).

\section{Temin's model: the Roman market economy}

The most elaborate critique of Bang's model is that by Morris Silver (2009). One of Silver's main criticisms was that "Bang underestimates the integration of the Roman economy" (Silver 2009: 422). Here we compare Bang's model with an alternative, which addresses this criticism: Temin's The Roman market economy (2013).

Temin's model of the Roman economy echoes many of Silver's arguments. Temin agrees with Bang that government involvement in the wheat trade was rather limited and that private enterprises dominated (2013: 32). He also agrees that ancient traders probably had access to far less commercial information than their counterparts in the modern world, and that local institutions and communities were crucial in disseminating information. Unlike Bang, however, Temin believes that Roman markets were integrated and strongly interconnected, even over large distances:

I argue that the economy of the early Roman Empire was primarily a market economy. The parts of this economy located far from each other were not tied together as tightly as markets often are today, but they still functioned as part of a comprehensive Mediterranean market (Temin 2013: 4).

Temin argues that simple models should be used to test the constituent concepts that comprise more sophisticated models. In this way, a good model may be distinguished from a bad one if it better fits the available data (Temin 2013: 5). Following on from this, we present the results of MERCURY (Market Economy and Roman Ceramics Redistribution, after the Roman patron god of commerce), an agent-based computational model that simulates the 
distribution of tablewares and compares the simulated output of different experiments with the distribution observed in the archaeological record.

\section{MERCURY: an agent-based computational model of tableware distribution}

A detailed technical description of MERCURY is published in Brughmans and Poblome (2016b). The code and documentation of MERCURY is available through the OpenABM repository (Brughmans \& Poblome 2015).

MERCURY simulates the structure of social networks between traders who act as channels for the flow of commercial information and goods. As the model is initialised, 1000 traders are distributed among 100 markets. Traders are subsequently connected in a social network with a high degree of clustering within markets and limited numbers of connections between clusters, which represents the community structure, using the algorithm for the creation of 'small-world' networks by Jin et al. (2001). A pair of traders connected in the social network are able to share commercial information (supply, demand and price estimates), and to trade tablewares. The integration of markets is high if the potential to share commercial information and goods directly between markets is high, and low if it is limited. The degree of market integration can therefore be represented as the proportion of all possible links that connect traders on different sites. If traders on one site have fewer links to traders on other sites, then their potential to obtain information and tableware is limited and the degree of integration between the two sites is low. This proportion is tested by changing the variable 'proportion-inter-site-links' in experiments (Figure 4). A high value for this variable represents highly integrated markets (Temin's hypothesis), while a low value represents weakly integrated markets (Bang's hypothesis).

Four of the markets are production centres of four different wares, and traders located at these markets obtain items of their locally produced ware in each time step. At each time step, all traders will determine the local demand for tableware, and will estimate an appropriate price based on their knowledge of the supply and demand of the traders to which they are connected. The availability of information is limited when a proportion of the traders that a trader is able to trade with does not share commercial information. This proportion is tested by adjusting the variable 'local-knowledge' in experiments. A low value for this variable represents the limited availability of accurate commercial information.

In each time step, every item of tableware is put up for sale, and pairs of traders who are connected in the network can buy or sell an item. When an item is successfully traded (if the transaction offers a break-even point or profit for the seller), the buyer will decide to either sell it to a local consumer in order to lower the demand at the market within which he is based (in which case the item is taken out of the trade system and is deposited at that market), or to store it for redistribution at a later time step if it promises a higher profit. Over time, as the tableware is traded and deposited at different sites, this model therefore gives rise to different patterns of distribution for the four tablewares. The two variables, the number of links between traders on different sites and the amount of information shared between connected traders, represent the key aspects of Bang's and Temin's hypotheses explored in our study. By changing the values of the two variables in separate experiments, we can

(C) Antiquity Publications Ltd, 2016 


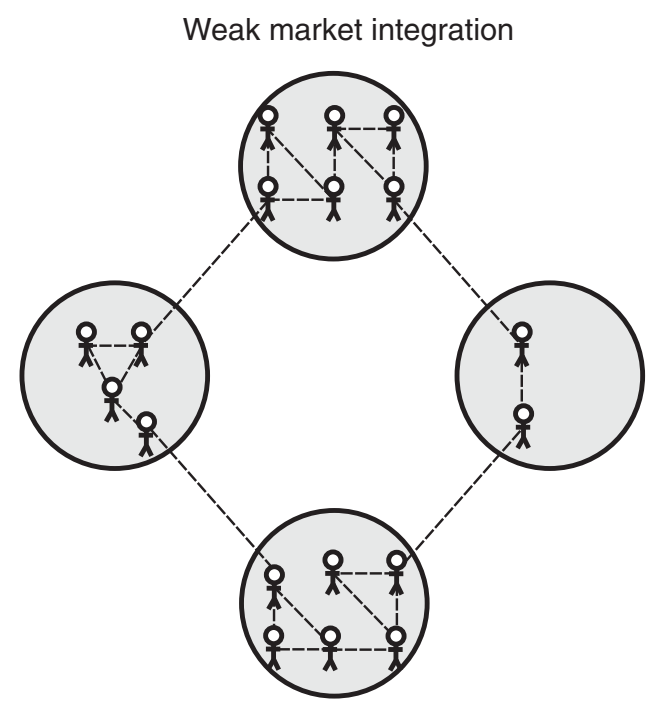

(a)

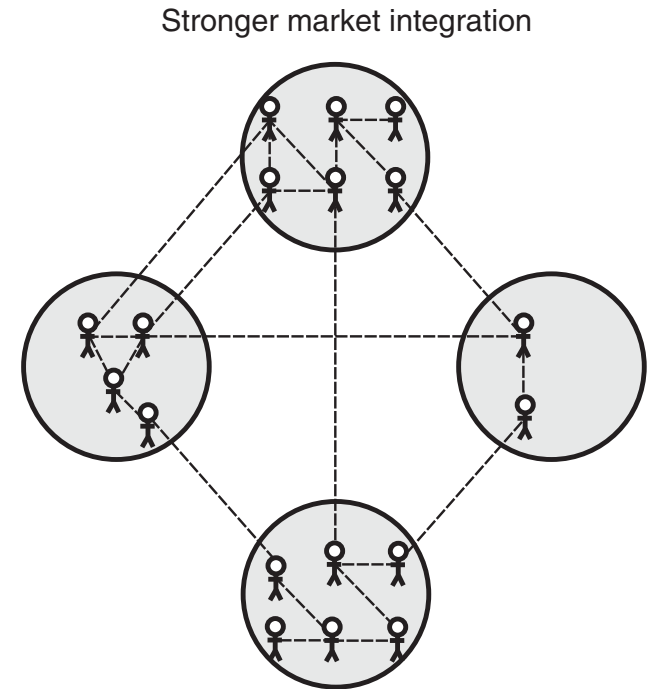

(b)

Figure 4. Abstract representation of the network structure created in MERCURY; in (a) the minimum degree of market integration is represented; in (b) a number (determined by the variable proportion-inter-site-links) of edges between pairs of traders on different sites is created, representing a higher degree of market integration.

explore what tableware distribution patterns are created, and also which factors do or do not give rise to the pattern observed in the archaeological record, i.e. under what conditions the tableware distribution is generally wide but in which one ware clearly dominates (Figure 1).

\section{Results}

Variable settings and summary results for each experiment presented in this paper are available via the online supplementary material (Table S2). The experiments show that differences in the availability of commercial information alone cannot explain the strong differences in tableware distributions observed in the ICRATES database for the earlier periods. Varying the proportion of contacts that a trader obtains commercial information from (local-knowledge variable) does not significantly affect the width of ware distribution (Figure 5). It does, however, affect the diversity of site assemblages: experiments with a high value for this variable result in less diverse assemblages (cf. the pattern shown in Figure 3) than those with a lower value. On the other hand, increasing the degree of market integration (by increasing the proportion-inter-site-links variable) gives rise to wider distributions and stronger differences, although these are, at best, only comparable to conditions in the period AD 100-150 (Figures 5 \& 6). 


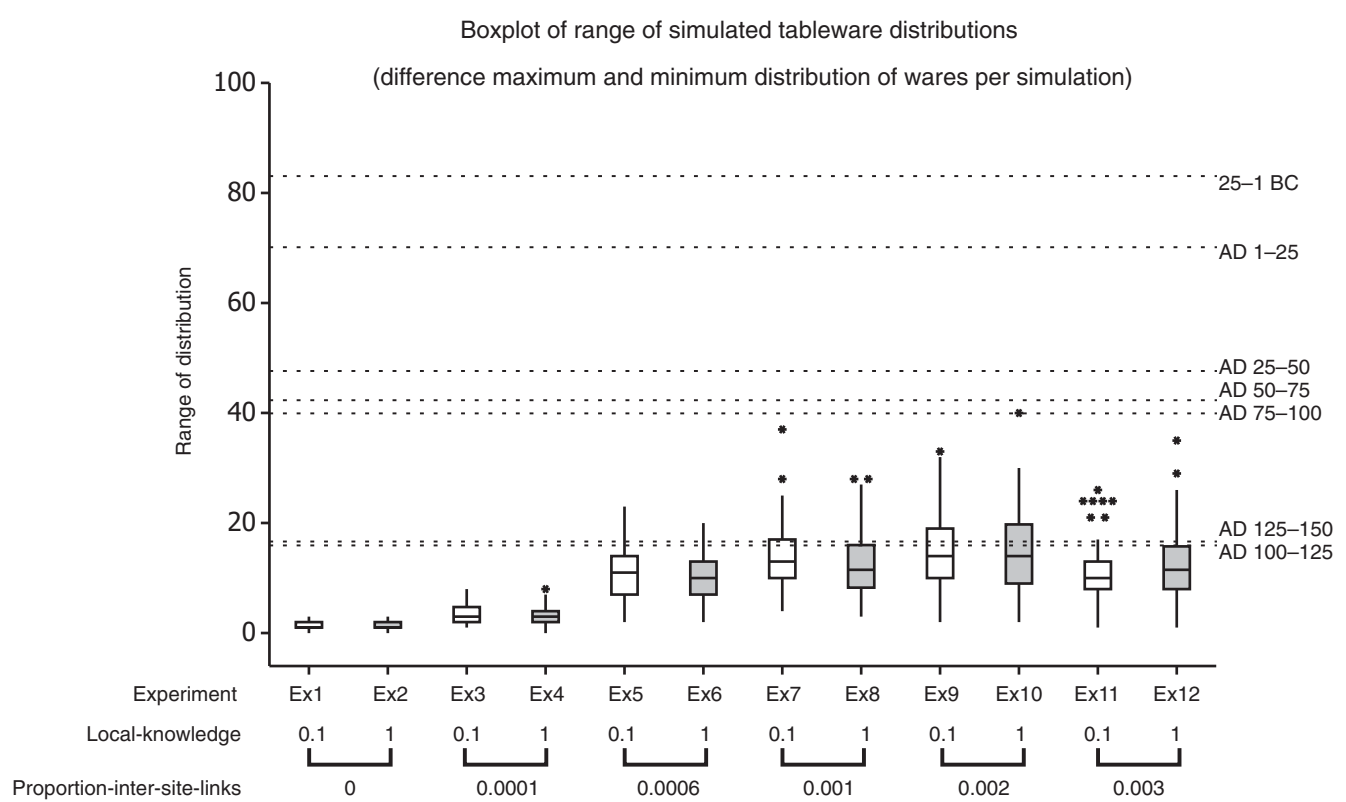

Figure 5. Boxplot of the range of simulated tableware distributions (100 simulations per experiment); boxplots for experiments with a low local-knowledge variable setting of 0.1 are in white, and those with a high setting of 1 , in grey; dotted lines represent the observed tableware distributions ranges presented in Figure 2 for comparison.

Furthermore, experiments with a high degree of market integration and an unequal number of traders at production centres result in very widely distributed wares and strong differences in distribution (Figure 7). Importantly, in experiments where all the other variable settings were fixed but the network structure is changed for a randomly created network, the width of wares' distributions is much higher, but the range remains similar on average (experiments $24 \& 29$; Figure 7; Table S2). Finally, in experiments where one production centre has far more traders than others, one ware will be far more widely distributed than the other wares (experiment 33; Figures $7 \& 8$ ). An experiment with the same variable settings but a randomly created network structure will result in a higher distribution range (experiment 34; Figure 7) and a wider overall distribution of all tablewares (Figure 8; Table S2).

\section{Discussion}

The results suggest that equal numbers of traders at production sites, low degrees of market integration and a limited availability of commercial information from direct trade contacts do not give rise to tableware distributions similar to those observed in the archaeological record (the ICRATES database). These three key results must be considered within their historical and archaeological contexts.

The simulated distributions best reflect the available archaeological data in scenarios where unequal numbers of traders are present at different production centres and are able to cater to a high, local demand. This observation highlights the importance of concerted (C) Antiquity Publications Ltd, 2016 
Boxplot of simulated distribution

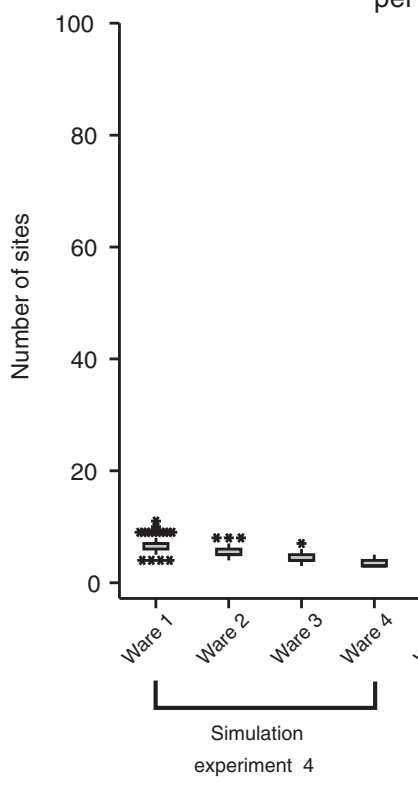

Proportion-inter-site-links

0.0001
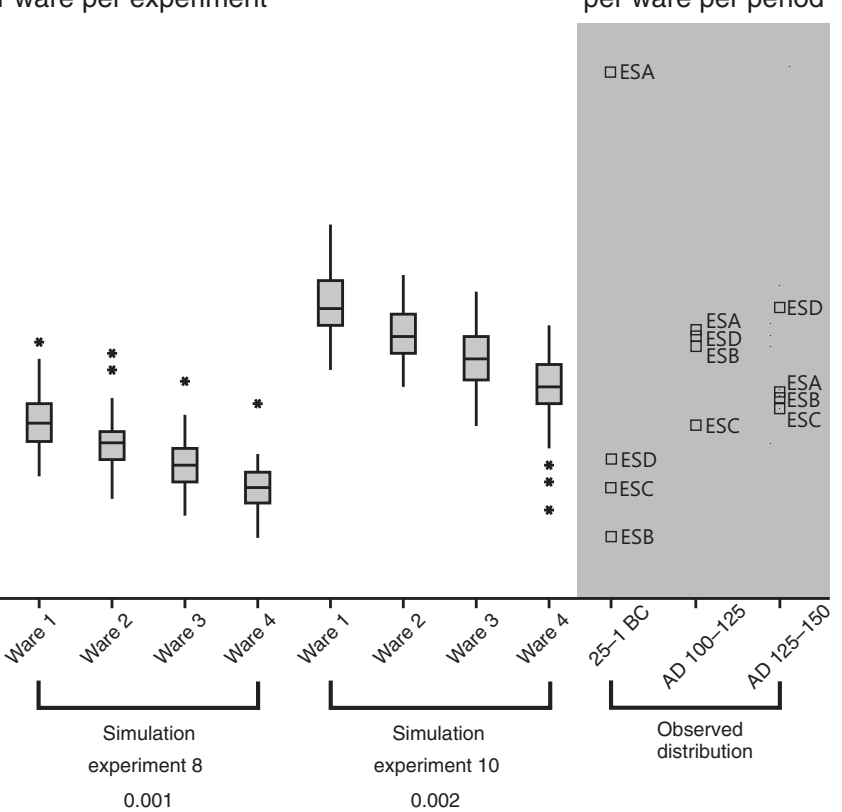

Figure 6. Boxplot of the width of distribution per ware ranked from the most (ware 1) to the least widely distributed (ware 4) (100 simulations per experiment); to the right, a grey background presents the observed width of tableware distributions for 25-1 BC and AD 100-150, as presented in Figure 1 for comparison.

supply and demand, typically associated with urban contexts. Unfortunately, the resolution of the available archaeological data is insufficient to compare the effects of specific sites, such as larger cities and smaller towns, in any great detail. We can only state that, in general, a large urban centre close to tableware production centres would have served as a primary market with a high demand, and therefore offered an impetus to produce large amounts of tableware. This mechanism has been proposed before for a variety of urban contexts based on descriptive, qualitative analyses of the ICRATES data (Poblome et al. 2012). MERCURY makes these assertions falsifiable however, thus enabling us to improve conceptual models by removing unnecessary elements and focusing future work on more promising factors; for example, the role of specific large urban centres in close proximity to presumed production centres, such as ancient Antioch or Ephesos.

Comparing the results of MERCURY with the ICRATES data provides further insights into the issue of market integration in Roman times. Only high proportions of inter-site links, representing a high integration of markets (as argued by Temin 2013), have the potential to give rise to the archaeologically observed differences in the width of tableware distributions. Through these links, traders obtain information about supply and demand (and thus price estimates) at different markets, and they enable traders to trade goods with others elsewhere. This observation implies that a significant proportion (but not necessarily a majority) of traders, communities or institutions must have had the financial and logistical ability to obtain information from other markets (through informants or 


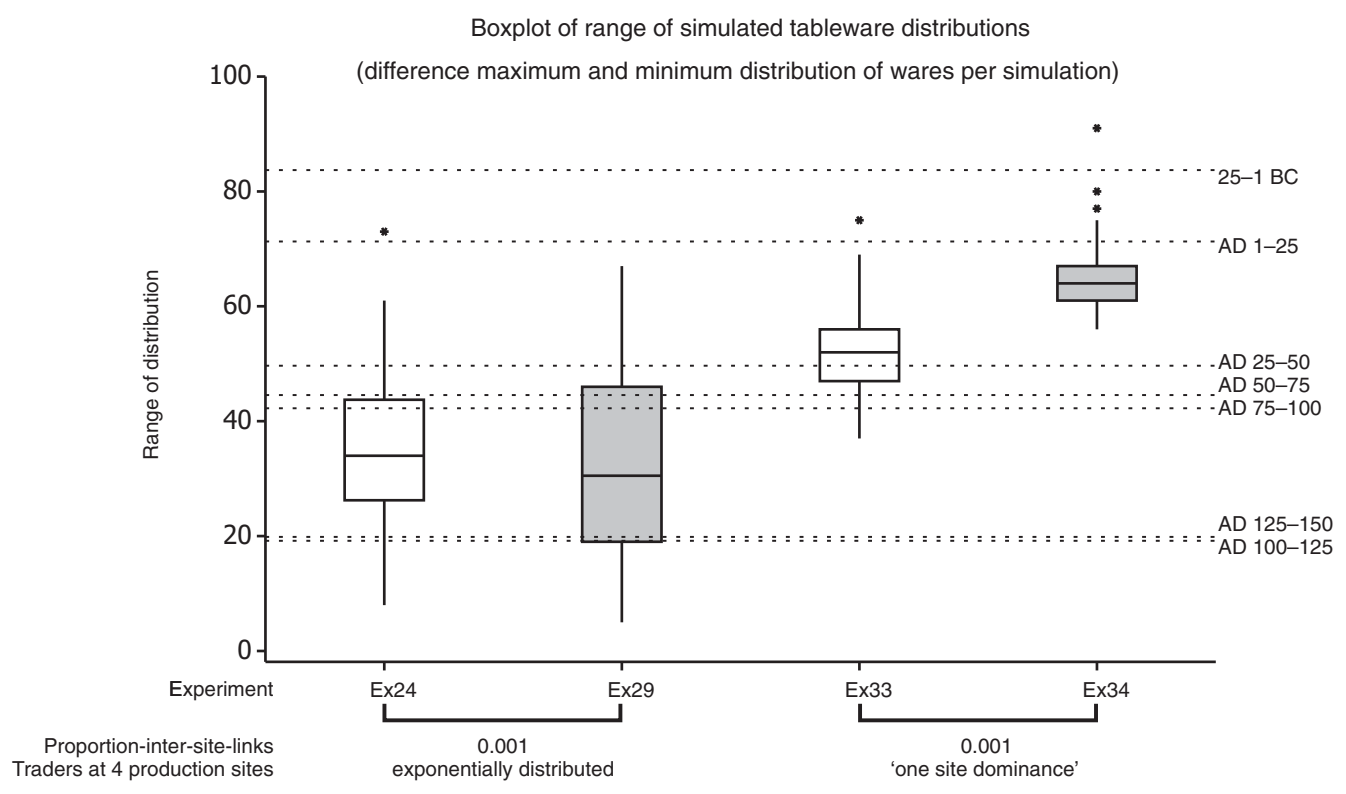

Figure 7. Boxplot of the range of simulated tableware distributions (100 simulations per experiment); boxplots for experiments with a randomly created network structure are in grey: dotted lines represent the observed tableware distribution ranges presented in Figure 2 for comparison; experiments where one production site has 30 traders and all of the three other production sites have only 1 trader are referred to as 'one site dominance'.

personally), and raises the question of whether regulations (civic, state or military) helped facilitate this scenario. The results of MERCURY suggest that future research should focus on these factors that enabled, structured and maintained communication between far away communities, giving rise to strong market integration.

Contrary to Bang's hypothesis, the results also show that under a wide range of parameter values, the community structure of the social network within individual markets is less important than a high degree of integration between markets and the potential for one production centre to produce more than others. Although the community structure of the social network can give rise to strong differences in tableware distributions, this happens only in scenarios with high market integration and with unequal production capabilities among the different tableware production centres.

In summary, MERCURY supports the following processes as contributing factors towards the archaeologically observed tableware distribution pattern: a high degree of market integration leads to generally widely distributed wares, while strong differences in the potential for large-scale production of tablewares results in variable distribution patterns among them.

\section{Conclusions: simulating the 'grey zone'}

We have formalised, tested and produced archaeologically verifiable predictions from the conceptual models offered by Bang and Temin. The results lead us to conclude that the limited integration of markets proposed by Bang's model is highly unlikely under the

(C) Antiquity Publications Ltd, 2016 


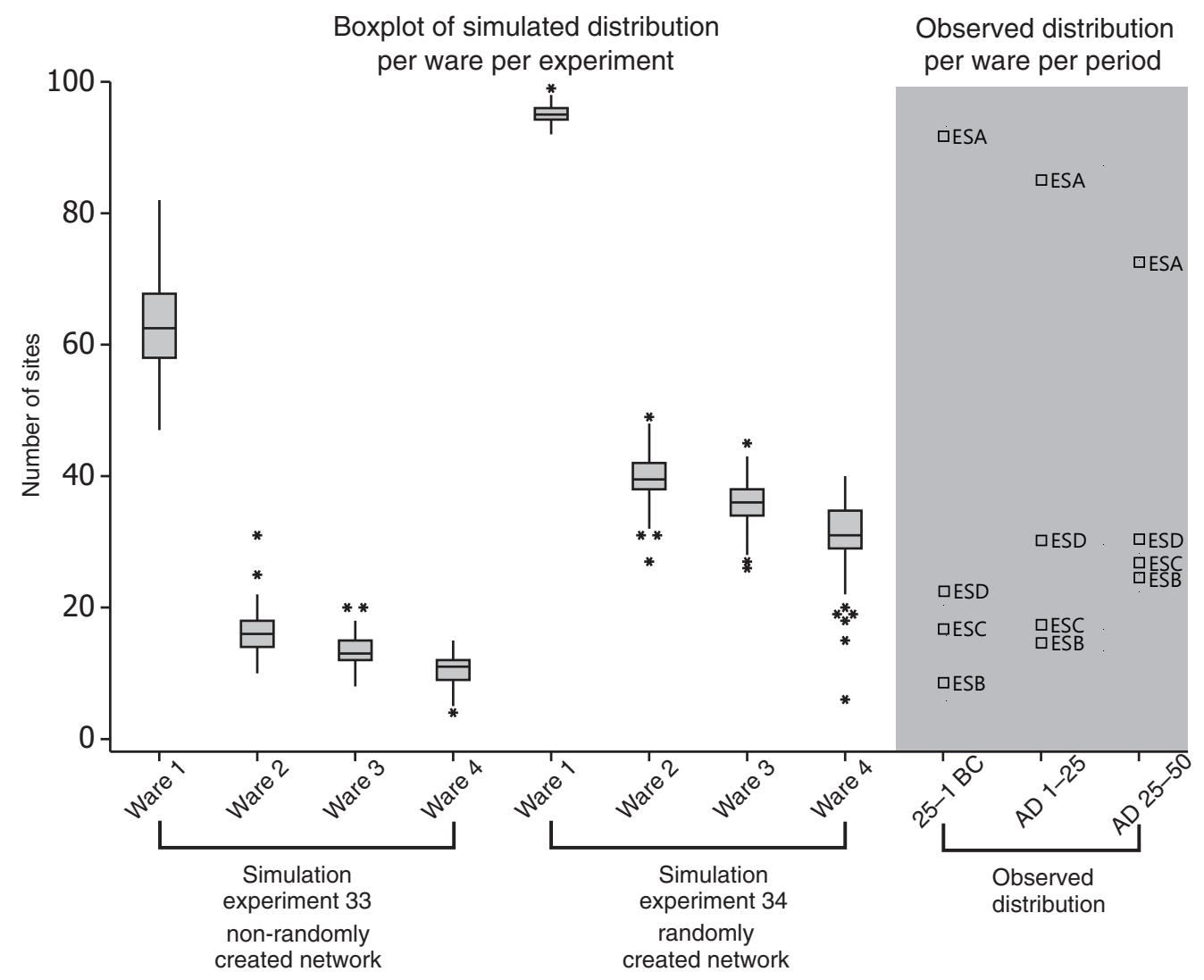

Figure 8. Boxplot of the width of distribution per ware ranked from the most (ware 1) to the least widely distributed (ware 4) (100 simulations per experiment); the right-hand side of this figure with a grey background presents the observed width of tableware distributions per period for $25 B C-A D 50$, as shown in Figure 1 for comparison.

conditions imposed in this study. The simulation confirmed the importance of market integration, as suggested by Temin's model, but it also highlighted the strong impact of other factors: differences in the potential production output of tableware production centres, and the demand of their local markets.

The results suggest that future research should place stronger focus on tableware production processes, and on the factors enabling market integration. The latter theme is most often approached by considering the gravitational pull of Rome in securing its food supplies (Scheidel 2014: 27-30). Our study, by contrast, presents a way to evaluate integration at different scales, with and without large urban centres. The approach can therefore be used to evaluate other explanatory factors, and it can be applied to other types of archaeological material and in other regions of the empire. Such factors include allocating the resources necessary for large-scale artisanal production, the varying roles and proportions of traders and institutions commercially active on multiple markets, the existence of large urban centres generating high demand for goods, their relation to tableware production centres, and the framework provided by the Roman Empire. These factors have been 
repeatedly debated by scholars of the Roman economy, but their highly complex nature means that their validity may only be tested and compared through a combination of exploratory archaeological data analysis and conceptual and computational modelling.

Given the abundance of conceptual models for explaining tableware distributions in the Roman East, and the agreement of most scholars that the Roman trade system was a complex affair influenced by multiple factors, we see at least four issues with the current debate over complex conceptual models that prevent progress in the study of the Roman economy:

1. Many models use different and sometimes ill-defined concepts to describe the complexities of the Roman economy, making them difficult to compare.

2. The concepts used often lack specifications as to how they may be explored using data, i.e. what sort of patterns would be expected as the outcome of hypothetical processes.

3. Consequently, the development of these conceptual models has not gone hand in hand with the development of approaches to represent, compare and (where possible) validate them formally.

4. The role of archaeological data in testing conceptual models, although increasingly recognised, deserves greater attention, as it is the only source of information on the functioning and performance of the Roman economy that can be used for quantitative validation of complex computational and conceptual models.

To begin challenging these issues, what is needed is an approach that: requires scholars to formulate models as well defined, explicit and comparable conceptualisations accompanied by data specifications and predictions; allows for the comparison of multiple hypothetical scenarios and the data patterns that these are predicted to produce; and allows for quantitative comparison with archaeological datasets. This study has illustrated that computational modelling meets these requirements. It allows probabilities to be attached to some factors, to map the 'grey zone' between extreme scenarios, and to falsify some of them. It also does not aim to restrict the study of the Roman economy to one way of conceptualising past phenomena, but emphasises the need to make models explicit and comparable. The potential of this computational approach, the importance of formulating complex hypotheses as comparable conceptualisations and the need to specify how these relate to archaeological data are by no means exclusive to the study of the Roman economy, but will prove a highly productive approach in archaeology in general. Small computational models such as MERCURY can be regarded as building blocks that allow elements of conceptual models to be tested in isolation, before assembling them together to improve our understanding of a complex, past system. Before this approach can fulfil its potential, however, the creation and discussion of conceptual models will need to happen in ways that open them to formal comparison, and the practice of building and critically evaluating computational models must become a more common practice.

\section{Acknowledgements}

This research was supported by the Belgian Programme on Interuniversity Poles of Attraction (IAP 07/09), the Research Fund of the University of Leuven (GOA 13/04) and Projects G.0562.11 and G.0637.15 of the Research Foundation Flanders (FWO). This work benefited from a research stay at the Belgian School in Rome, funded by a Stipendium Academia Belgica. Part of this paper was written during employment on the

(C) Antiquity Publications Ltd, 2016 
CARIB project, and financially supported by the HERA Joint Research Programme, which is co-funded by AHRC, AKA, BMBF via PT-DLR, DASTI, ETAG, FCT, FNR, FNRS, FWF, FWO, HAZU, IRC, LMT, MHEST, NWO, NCN, RANNÍS, RCN, VR and The European Community FP7 2007-2013, under the Socio-economic Sciences and Humanities programme. We would like to thank Fraser Sturt, Andy Bevan, Simon Keay, Graeme Earl, Iza Romanowska, Elizabeth Fentress and Martin Millett for helpful comments on drafts of this paper. We thank Philip Bes, Rinse Willet and others who contributed to the ICRATES database.

\section{Supplementary material}

To view supplementary material for this article, please visit http://dx.doi.org/10.15184/ aqy.2016.35

\section{References}

ABADIE-ReYnal, C. 1989. Céramique et commerce dans le bassin Egéen du IVe au VIIe siecle, in V. Kravari, J. Lefort \& C. Morrisson (ed.) Hommes et richesses dans l'empire byzantin. Tome I, IVe-VIIe siècle: 143-59. Paris: Éditions P. Lethielleux.

BANG, P.F. 2008. The Roman bazaar, a comparative study of trade and markets in a tributary empire. Cambridge: Cambridge University Press.

BES, P. 2015. Once upon a time in the East. The chronological and geographical distribution of Terra Sigillata and Red Slip Ware in the Roman East (Roman and Late Antique Mediterranean Pottery 6). Oxford: Archaeopress.

Bes, P. \& J. Poblome. 2008. (Not) see the wood for the trees? $19,700+$ sherds of sigillata and what we can do with them ... Rei Cretariae Romanae Fautorum Acta 40: 505-14. Bonn: Dr Rudolf Habelt.

Brughmans, T. \& J. Poblome. 2015. MERCURY: an $\mathrm{ABM}$ of tableware trade in the Roman East. CoMSES Computational Model Library. Available at: https://www.openabm.org/model/4347/version/2/ view (accessed 7 January 2016)

- 2016a. Pots in space: understanding Roman pottery distribution from confronting exploratory and geographical network analyses, in E. Barker, S. Bouzarovski, C. Pelling \& L. Isaksen (ed.) New worlds from old texts: revisiting ancient space and place: 255-80. Oxford: Oxford University Press.

- 2016b. MERCURY: an agent-based model of tableware trade in the Roman East. Journal of Artificial Societies and Social Simulation 19(1). Available at: http://jasss.soc.surrey.ac.uk/19/1/3.html.

DAVIES, J.K. 2005. Linear and nonlinear flow models for ancient economies, in J.G. Manning \& I. Morris (ed.) The ancient economy: evidence and models: 127-56. Stanford (CA): Stanford University Press.
Fentress, E. \& P. Perkins. 1988. Counting African Red Slip Ware, in A. Mastino (ed.) L'Africa Romana: Atti del V Convegno di studio Sassari, 11-13 dicembre 1987: 205-14. Sassari:

Dipartimento di storia, Università degli studi di Sassari.

Graham, S. \& S. WeIngart. 2015. The equifinality of archaeological networks: an agent-based exploratory lab approach. Journal of Archaeological Method and Theory 22: 248-74.

http://dx.doi.org/10.1007/s10816-014-9230-y

HAYES, J.W. 1972. Late Roman pottery. London: British School at Rome.

- 1985. Sigillate orientale, in G.P. Carratelli (ed.) Enciclopedia dell'arte antica. classica e orientale. Atlante della forme ceramiche II: ceramica fine romana nel bacino mediterraneo (tardo ellenismo e primo imperio): 1-96. Rome: Enciclopedia Italiana.

Jin, E.M., M. Girvan \& M.E. NewMan. 2001. Structure of growing social networks. Physical review. E, Statistical, nonlinear, and soft matter physics 64: 046132. http://dx.doi.org/10.1103/PhysRevE.64.046132

LEWIT, T. 2011. Dynamics of fineware production and trade: the puzzle of supra-regional exporters. Journal of Roman Archaeology 24: 313-32. http://dx.doi.org/10.1017/S1047759400003391

MeYer-SCHLichtMann, C. 1988. Die pergamenischen Sigillata aus der Stadtgrabung von Pergamon. Mitte 2. JH v. Chr.-Mitte 2. JH n. Chr. Berlin \& New York: de Gruyter.

Morris, I., R.P. SALLER \& W. SCHEIDEL. 2007. Introduction, in W. Scheidel, I. Morris \& R.P. Saller (ed.) The Cambridge economic history of the Greco-Roman world: 1-12. Cambridge: Cambridge University Press.

Poblome, J. 2013. Money makes pottery go round, in J. Poblome (ed.) Exempli Gratia. Sagalassos, Marc Waelkens and interdisciplinary archaeology: 81-95. Leuven: Leuven University Press. 
Poblome, J., P. Bes \& R. Willet. 2012. Thoughts on the archaeological residue of networks. A view from the East, in S. Keay (ed.) Rome, Portus and the Mediterranean (Archaeological Monographs of the British School at Rome 21): 393-401. London: British School at Rome.

REYNOLDS, P. 1995. Trade in the Western Mediterranean, AD 400-700: the ceramic evidence (British Archaeological Reports international series 604). Oxford: Archaeopress.

SCHEIDEL, W. 2014. The shape of the Roman world: modelling imperial connectivity. Journal of Roman Archaeology 27: 7-32. http://dx.doi.org/10.1017/S1047759414001147
SCHNeIder, G. 2000. Chemical and mineralogical studies of late Hellenistic to Byzantine pottery production in the Eastern Mediterranean. Rei Cretariae Romanae Fautorum Acta 36: 525-36.

Silver, M. 2009. Historical otherness, the Roman Bazaar and primitivism. Journal of Roman Archaeology 22: 421-40.

http://dx.doi.org/10.1017/S1047759400020821

Temin, P. 2013. The Roman market economy. Princeton (NJ): Princeton University Press.

WILLET, R. 2014. Experiments with diachronic data distribution methods applied to Eastern Sigillata A in the eastern Mediterranean. HEROM: Journal on Hellenistic and Roman Material Culture 3: 39-69.

Received: 16 January 2015; Accepted: 8 April 2015; Revised: 29 May 2015

(C) Antiquity Publications Ltd, 2016 